\title{
Irradiance characteristic of a small-scale solar simulator for testing thermal collectors
}

\author{
Adina-Teodora Gheorghian, ${ }^{1, *}$, Valentin Apostol ${ }^{1}$, Tudor Prisecaru ${ }^{1}$, Camelia Stanciu ${ }^{1}$ and \\ Horațiu Pop ${ }^{1}$ \\ ${ }^{1}$ Politehnica University of Bucharest, Department of Engineering Thermodynamics, 313 Splaiul \\ Independentei, 060042, Bucharest, Romania
}

\begin{abstract}
This paper describes the development of a small-scale solar simulator for research and educational purposes. The main goal is to provide a uniform and stable distribution of irradiation from a set of four floodlight halogen lamps, over a targeted area of $40 \times 40 \mathrm{~cm}^{2}$. The floodlights are placed perpendicularly to each other, on the top end of a light tube. Two types of halogen lamps were characterised and the total irradiation of the solar simulator was measured over a $5 \times 5$ grid. The results showed that the two arrangements of lamps are able to achieve a level of $1000 \mathrm{~W} / \mathrm{m}^{2}$ on the $40 \times 40 \mathrm{~cm}^{2}$ targeted area, but the non-uniformity is unsatisfactory. In order to reach a non-uniformity level of $10 \%$ using the proposed lamps arrangements, the targeted area should be reduced to $31 \times 31 \mathrm{~cm}^{2}$.
\end{abstract}

\section{Introduction}

Thermal collectors are often tested indoors using a solar simulator that provides uniform and stable irradiance at certain levels.

The development of a solar simulator for indoor testing and the certification procedure for photo-thermal solar devices is discussed in [1]. The solar simulator consists of 14 Philips no. 13989 R quartz halogen lamps (1000 W, $25000 \mathrm{~lm}, 3200 \mathrm{~K})$ mounted in a Philips NV 51 luminaire with built-in reflectors and provide a testing area of about $1 \times 1 \mathrm{~m}^{2}$. The power of the lamps can be modified by means of adjustable transformers. Thus, the radiation at the testing area level can be adjusted between 400 and $1500 \mathrm{~W} / \mathrm{m}^{2}$. The irradiance distribution over the testing area has been recorded using a precision Eppley pyranometer.

The light source and production of an economical large-scale solar simulator is presented in [2]. The solar simulator consists of 188 lamps (400 Watt, metal halide gas discharge type), mounted on a steel frame $(4.5 \times 3.88 \mathrm{~m})$ and four variable speed elevators, which are either manually or computer controlled. Measurements of the irradiance indicates that the simulator conforms to Class B of the ASTM E927 (2005) and 60904-9 (2007) standard in regard to spectrum match, irradiance uniformity and stability. The average irradiance on the targeted area can be adjusted from 150 to $1100 \mathrm{~W} / \mathrm{m}^{2}$ by varying the number of lamps and/or the lamp-to-area distance.

* Corresponding author: adina gheorghian@yahoo.com 
Paper [3] describes an empirical method for evaluating a solar simulator testing facility based on an experimental performance. For testing evacuated solar collectors, a sunlight simulator comprising of an array of 30 halogen floodlights (400 W, $3200 \mathrm{~K}$ ) covering an area of $2.32 \mathrm{~m}^{2}$ has been assembled and analysed. The halogen lamps were divided into groups of 10 pieces. The three groups of halogen floodlights were connected to the grid via a three-phase adjustable transformer, which allowed continuous adjustment of the power consumption and, implicitly, of the irradiation intensity. The authors showed that the higher the radiation intensity, the greater the non-uniformity of irradiation. Maximum nonuniformity based on experimental data was $9.1 \%$, less than the $15 \%$ limit set in British standards for solar simulator performance.

A simple solar simulator which consists of one $300 \mathrm{~W}$ halogen lamp, a Luxmeter (Lutron LX-101A), and solar panel holders placed on a closed light box with the dimension of $40 \times 40 \times 40 \mathrm{~cm}^{3}$ is described in [4]. The spatial distribution of irradiation inside the light box was theoretically estimated with the Monte Carlo method and experimentally validated using a luxmeter. It was found that the theoretical and the experimental data are in good agreement and the irradiation uniformity was acceptable inside the light box.

Paper [5] presents a development of a solar simulator for education and research purposes. The simulator was built using eight $500 \mathrm{~W} / 220 \mathrm{~V}$ halogen lamps. Two groups of four lamps were connected in series, and then the two groups were connected in parallel. The lamps were placed in the nodes of a $2 \times 4$ equidistant grid, perpendicularly to each other. The irradiation produced by the eight lamps was measured with a pyranometer at different distances between reflectors and different distances up to the target area. Experiments have shown that the uniformity and intensity of irradiation are appropiate when the distance between the reflectors is $15 \mathrm{~cm}$ and the distance to the target plane is between 20 and 40 $\mathrm{cm}$.

A solar simulator using an internally reflecting light tube has been designed and built for testing small size $(0.5 \times 0.5 \mathrm{~m})$ flat plate thermal collectors [6]. Four halogen floodlights were placed at the top end of the light tube to ensure uniform illumination. Ray-tracing simulations were used to choose the tube dimensions and maximum allowable distance from the lower end of the light tube to the collector. Simulations carried out with this solar simulator show that the efficiency of the solar collector based on the pyranometer's readings is approximately $1 \%$ higher than it would have been obtained when using an AM1.5 spectrum.

Paper [7] is aimed at discussing in detail the development, characteristics and calibration of a simple low cost solar simulator using 16 halogen lamps $(50 \mathrm{~W}, 110 \mathrm{~V})$ mounted on an aluminium plate of $380 \mathrm{~mm} \times 350 \mathrm{~mm}$ as light sources. The non-uniformity of irradiance values were investigated at different distances D between the light surface simulator and solar collector's surface and the maximum non-uniformity was found to be $\sim 12 \%$ (at $\mathrm{D}=32 \mathrm{~cm}$ ).

This paper presents the development and characterization of a solar simulator using four halogen floodlights and a light tube for testing flat plate thermal collectors with a maximum targeted area of $400 \times 400 \mathrm{~mm}^{2}$. The design of the solar simulator is similar to those described in paper [6].

\section{Experimental set up and procedure}

\subsection{Irradiance distribution of the floodlight}

During the first stage, the intensity and distribution of radiation produced by a single floodlight was determined experimentally over a plane located one meter below. The 


\section{TE-RE-RD 2019}

measurements were carried out with two different types of halogen lamps, in order to determine which one ensures the maximum required irradiation level.

The shape and appearance of the two lamps used in the experiment are shown in Fig. 1.

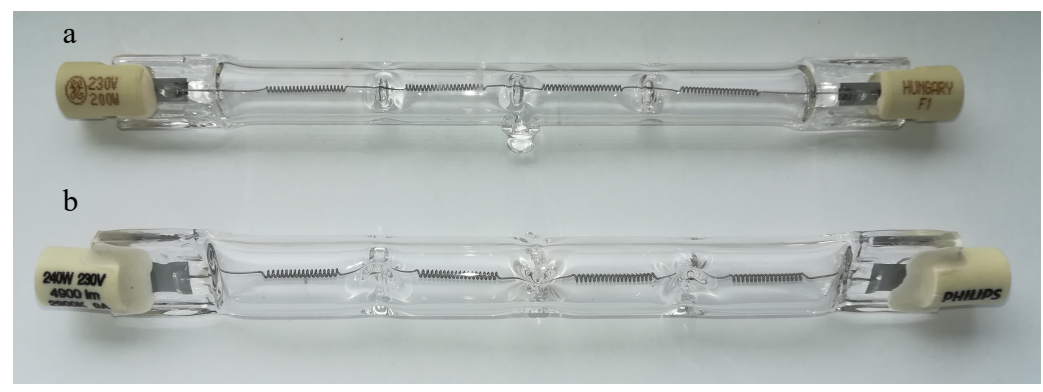

Fig. 1. The selected lamps for experiment: a - Halogen Linear OT K9 C200W 230V R7S 117MM GE General Electric; b - Plusline ES Small 118mm 2y 240W R7s 230V 1BB Philips

The comparison between the lamps with respect to performance and electrical data is presented in Tables 1, 2 and 3.

Table 1. Halogen lamps - Product data

\begin{tabular}{|c|c|c|c|c|c|}
\hline Brand & $\begin{array}{c}\text { Product } \\
\text { code }\end{array}$ & $\begin{array}{c}\text { Bulb } \\
\text { shape }\end{array}$ & $\begin{array}{c}\text { Bulb } \\
\text { diameter }\end{array}$ & $\begin{array}{c}\text { Overall } \\
\text { Length }\end{array}$ & Cap/Base \\
\hline & & & $\mathrm{mm}$ & $\mathrm{mm}$ & - \\
\hline General Electric & 64968 & tubular & 8 & 119 & $\mathrm{R} 7 \mathrm{~s}$ \\
\hline $\begin{array}{c}\text { Philips Plusline } \\
\text { ES Small }\end{array}$ & $\begin{array}{c}87279008 \\
5380300\end{array}$ & tubular & 12 & 117.6 & $\mathrm{R} 7 \mathrm{~s}$ \\
\hline
\end{tabular}

Table 2. Halogen lamps - Performance data

\begin{tabular}{|c|c|c|c|c|c|}
\hline Brand & $\begin{array}{c}\text { Rated } \\
\text { efficacy }\end{array}$ & $\begin{array}{c}\text { Energy } \\
\text { efficiency }\end{array}$ & $\begin{array}{c}\text { Rated } \\
\text { Life }\end{array}$ & $\begin{array}{c}\text { Color } \\
\text { temp. }\end{array}$ & $\begin{array}{c}\text { Nominal } \\
\text { lumens }\end{array}$ \\
\hline $\mathrm{lm} / \mathrm{W}$ & - & $\mathrm{h}$ & $\mathrm{K}$ & $\mathrm{lm}$ \\
\hline General Electric & 20 & $\mathrm{C}$ & 2000 & 3000 & 4000 \\
\hline $\begin{array}{c}\text { Philips Plusline } \\
\text { ES Small }\end{array}$ & 20.4 & $\mathrm{C}$ & 2000 & 2900 & 4900 \\
\hline
\end{tabular}

Table 3. Halogen lamps - Electrical data

\begin{tabular}{|c|c|c|c|c|c|}
\hline Brand & $\begin{array}{c}\text { Switching } \\
\text { cycles }\end{array}$ & Coil type & $\begin{array}{c}\text { Dimming } \\
\text { Capability }\end{array}$ & $\begin{array}{c}\text { Nominal } \\
\text { power }\end{array}$ & $\begin{array}{c}\text { Nominal } \\
\text { voltage }\end{array}$ \\
\hline & - & - & - & W & V \\
\hline General Electric & 8000 & CC-8 & yes & 200 & 230 \\
\hline $\begin{array}{c}\text { Philips Plusline } \\
\text { ES Small }\end{array}$ & 8000 & & yes & 240 & 230 \\
\hline
\end{tabular}

The selected lamps were inserted into a symmetrical model 0201 HEPOL floodlight (Figure 2). 


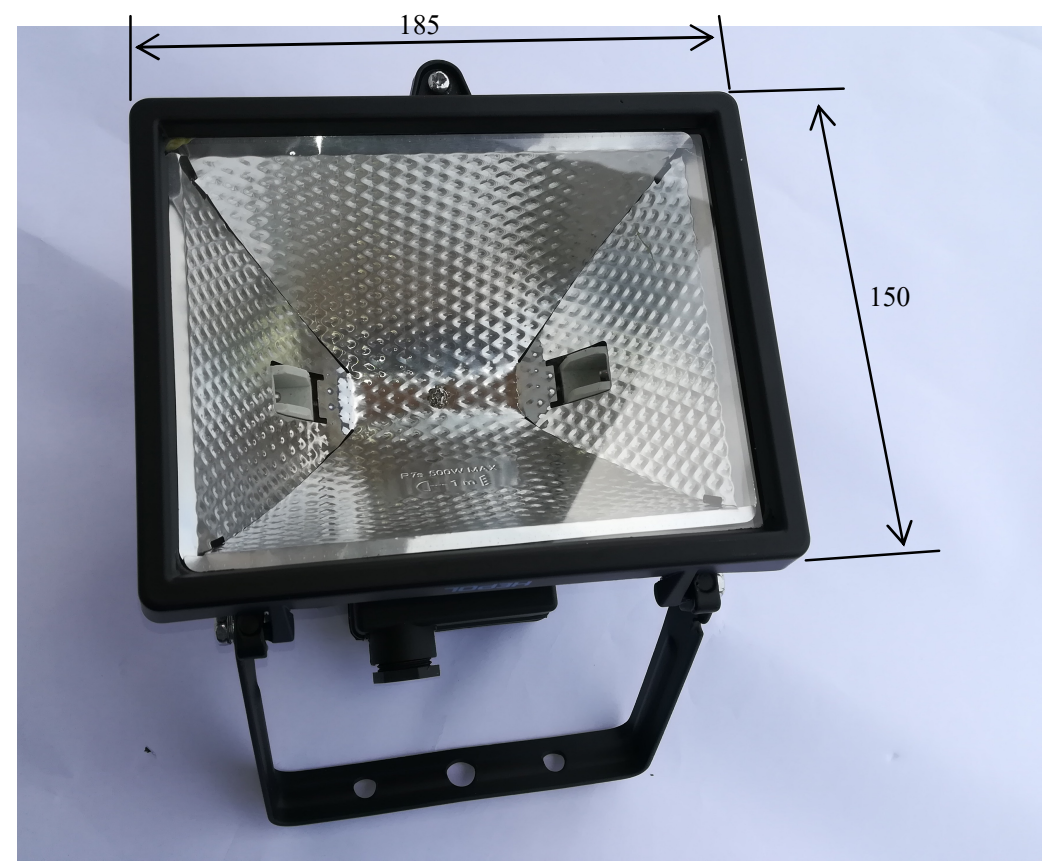

Fig. 2. Symmetrical floodlight model $0201 \mathrm{HEPOL}$

The intensity of the irradiation produced by the floodlight over the targeted plane was measured using a pyranometer at several equidistant points along the two perpendicular axes, $\mathrm{xx}$ and yy, defined as shown in the scheme in Figure 3.

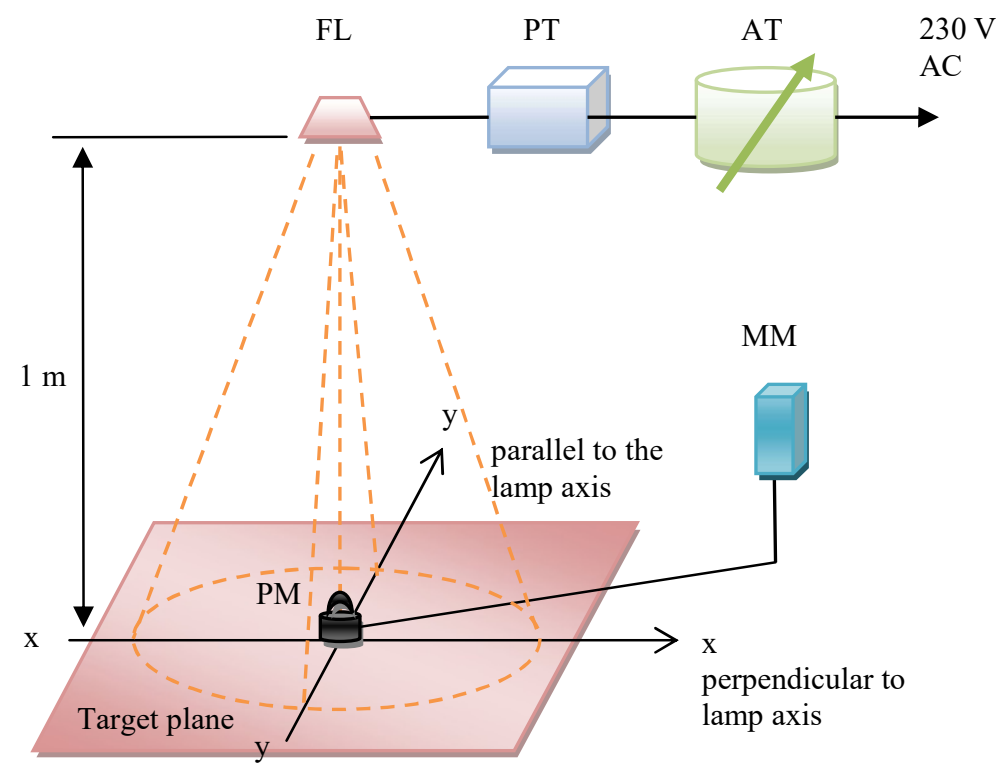

Fig. 3 Schematic of irradiation measurement setup: FL - HEPOL floodlight; PT - SIRAX BT5400 power transducer; AT - HSN METREL adjustable transformers; MM - FLUKE 87 V multimeter; PM - EKO MS-60 first class pyranometer 
The power input of the lamp was monitored on the power transducer display. During measurements, the input power of the lamp was kept constant and equal to the nominal power of the lamp by means of the adjustable transformer. The irradiance was read on the multimeter's display and recorded manually, from 5 to 5 centimetres, along the axis. Figure 4 reveals the irradiation distribution of each tested lamp.

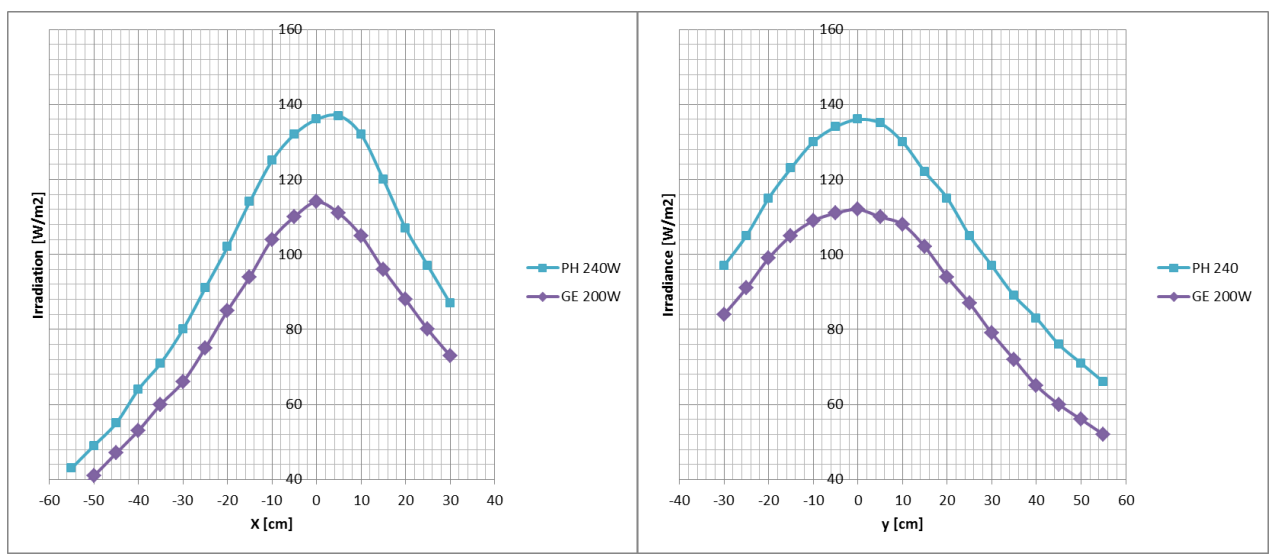

Fig. 4. Distribution of lamp irradiation perpendicular to lamp axis (left) and parallel to lamp axis (right)

As expected, the $240 \mathrm{~W}$ Philips lamp is brighter than the $200 \mathrm{~W}$ General Electric lamp by about $24 \mathrm{~W} / \mathrm{m}^{2}$ in the centre and by only $10 \mathrm{~W} / \mathrm{m}^{2}$ at the edges. Comparing the two charts, it can be noticed that irradiance along the $\mathrm{x}$ axis is stepper than the one along the $\mathrm{y}$ axis, which is due to the cylindrical (linear) bulb shape.

\subsection{Irradiance distribution of the solar simulator}

To reduce irradiation's non-uniformity over the target plane, the four floodlights of the solar simulator were placed equidistantly on a circle and rotated $90^{\circ}$ apart from each other on the top end of the light tube, as shown in Figure 5.

The walls of the light tube were made of $10 \mathrm{~mm}$ OSB plywood, reinforced with $24 \mathrm{x} 48$ $\mathrm{mm}$ timber laths on the edges. An aluminium foil was previously glued using BISON Colla ${ }^{\mathrm{TM}}$ spray adhesive, on the inner surface of the tube walls, in order to get a proper reflective surface for the floodlights.

The power transducer and the multimeter were attached on the outer surface of the light tube (see Figure 6).

Similarly to the previous experiment, the input power of the four floodlights was kept constant and equal to four times the nominal power of the lamp, while the irradiance was measured by reading the multimeter's display in 25 locations on a $5 \times 5$ grid (the distance between two adjacent points of the grid on $\mathrm{x}$ or $\mathrm{y}$ direction was $10 \mathrm{~cm}$, so the targeted area was $40 \times 40 \mathrm{~cm}^{2}$ ). 

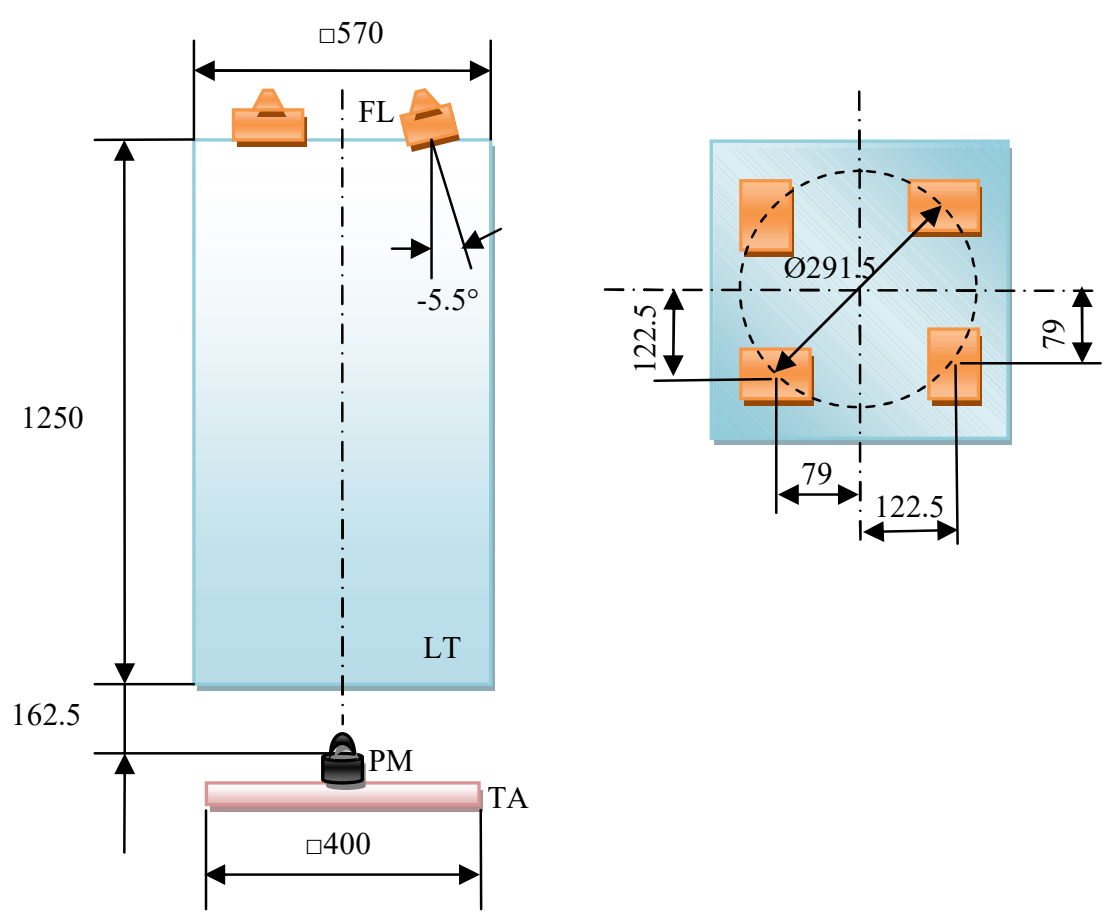

Fig. 5 The arrangement of the floodlights on the top of the light tube: FL - floodlight; LT - light tube; PM - pyranometer; TA - tageted area

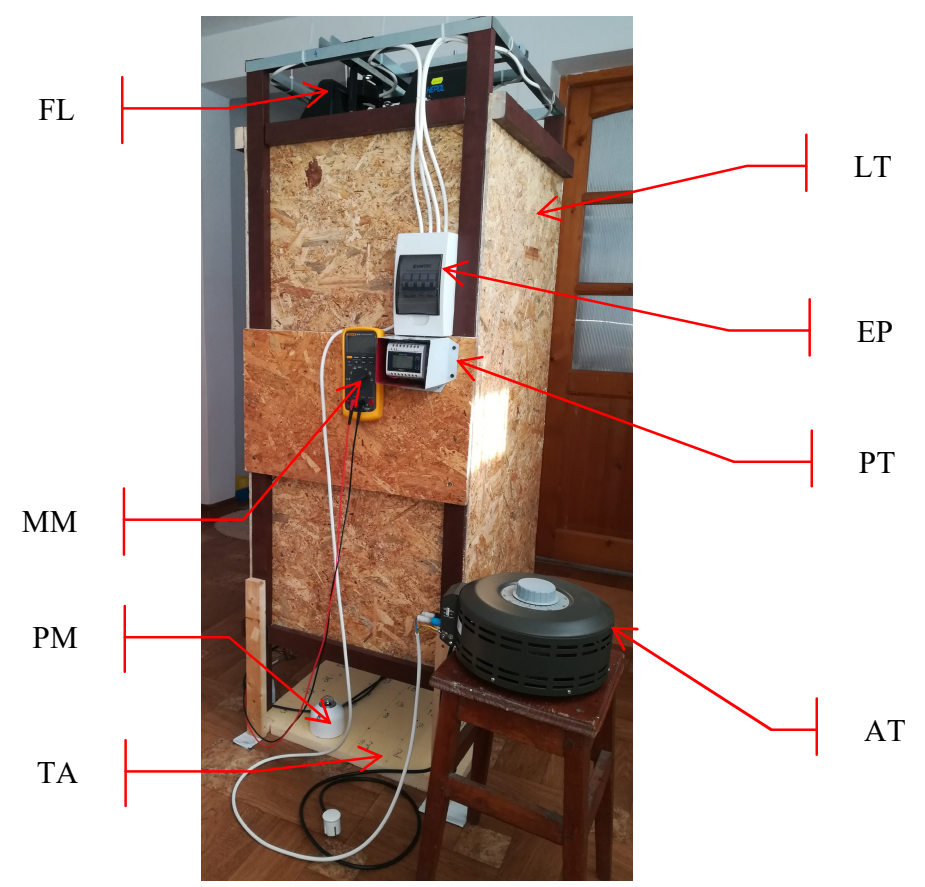

Fig. 6 View of the solar simulator: FL - floodlight; EP - electric panel; PT- power transducer; LT light tube; AT - adjustable transformer; MM- multimeter; PM - pyranometer; TA - targeted area 


\section{Results and discussion}

Figure 7 shows the results for the four floodlights arranged on the top of the light tube as presented in Fig. 5.

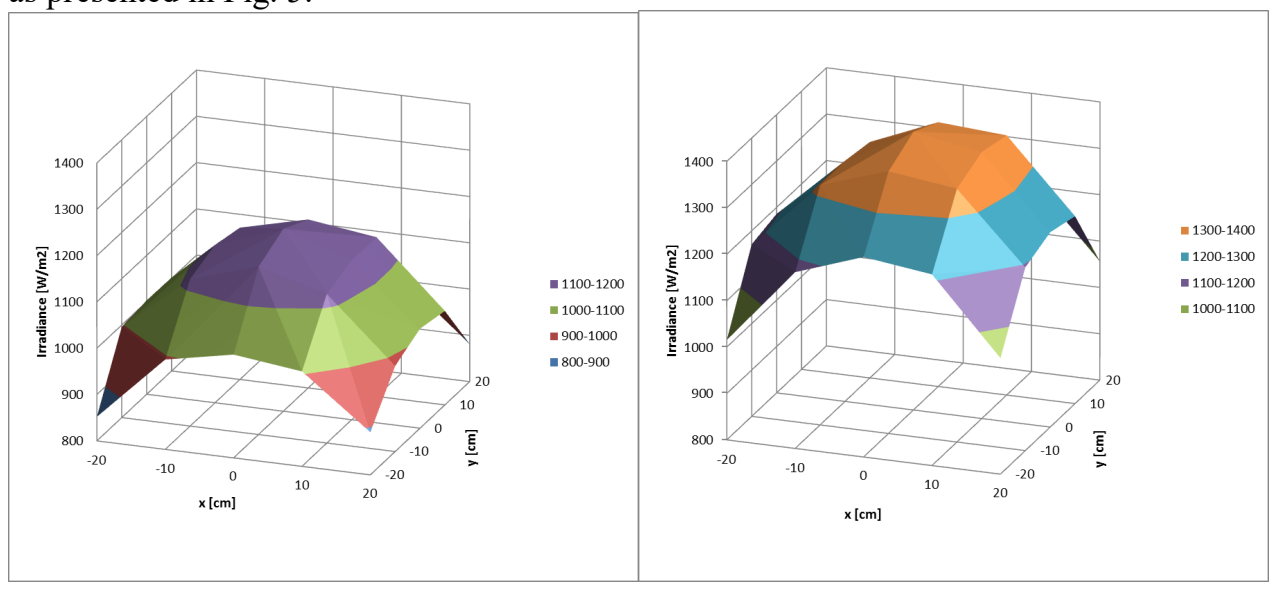

Fig. 7 The irradiation distribution over the targeted area: 4x200W General Electric lamps (left) and 4x240W Philips Plusline ES Small lamps (right)

The statistics of the two sets of experimental data are summarized in Table 4.

Table 4. Irradiance statistics

\begin{tabular}{|c|c|c|c|c|c|}
\hline Lamp & Mean & Min & Max & SD & $\begin{array}{c}\text { Non } \\
\text { uniformity }\end{array}$ \\
\hline- & $\mathrm{W} / \mathrm{m}^{2}$ & $\mathrm{~W} / \mathrm{m}^{2}$ & $\mathrm{~W} / \mathrm{m}^{2}$ & $\mathrm{~W} / \mathrm{m}^{2}$ & $\%$ \\
\hline $4 \times 200 \mathrm{~W}$ General Electric & 1035.6 & 852.0 & 1194.0 & 98.1 & 16.7 \\
\hline $\begin{array}{c}4 \times 240 \mathrm{~W} \text { Philips Plusline ES } \\
\text { Small }\end{array}$ & 1226.2 & 1000 & 1403.0 & 115.7 & 16.8 \\
\hline
\end{tabular}

According to the IEC 60904-9 international standard, the non-uniformity of the irradiance on the test plane is

$$
\text { non_uniformity }=\left(\max _{\mathrm{irr}}-\min _{\mathrm{irr}}\right) /\left(\max _{\mathrm{irr}}+\min _{\mathrm{irr}}\right) \cdot 100 \%,
$$

where the maximum and minimum irradiance were measured using the pyranometer over the tested area.

The average area mean irradiation computed by integration on the $40 \times 40 \mathrm{~cm}^{2}$ targeted area was $1076.76 \mathrm{~W} / \mathrm{m}^{2}$ for $4 \times 200 \mathrm{~W}$ General Electric lamps and $1273.67 \mathrm{~W} / \mathrm{m}^{2}$ for $4 \times 240 \mathrm{~W}$ Philips Plusline lamps, therefore both arrangements are able to ensure a mean irradiance of $1000 \mathrm{~W} / \mathrm{m}^{2}$. However, as one may notice from Figure 7 and the Table 4, both arrangements display a low level of irradiance in the corners of the $40 \times 40 \mathrm{~cm}^{2}$ targeted area. The non-uniformity of the irradiation is significantly lower than $10 \%$ as provided ASTM and IEC standards for C class simulators.

The additional calculations show that using these arrangements, the surface of targeted area should be reduced to $31 \times 31 \mathrm{~cm}^{2}$ in order to achieve a $\mathrm{C}$ class non-uniformity. 


\section{Conclusions}

Based on the experimental study presented in this paper, the following concluded remarks have been made:

- The main purpose of this study was to develop a solar simulator capable of producing a stable and uniform irradiation with adjustable intensity between 400 and $1000 \mathrm{~W} / \mathrm{m}^{2}$, over a targeted area of $40 \times 40 \mathrm{~cm}^{2}$, for testing prototypes of thermal plane collectors;

- The study was carried out for research and educational purposes, using two types of halogen lamps;

- The four floodlights are placed on the top end of a 57x57x125 cm light tube, with a clearance of $16.2 \mathrm{~cm}$, and wired to an electrical circuit which enables accurate measurements and adjustments of input power and irradiance levels;

- The two lamps arrangements are able to achieve a level of $1000 \mathrm{~W} / \mathrm{m}^{2}$ on the 40x40 targeted area, but the non-uniformity has high values;

- In order to achieve a non-uniformity level of $10 \%$ using the studied arrangements of lamps, the targeted area should be reduced from $40 \times 40 \mathrm{~cm}^{2}$ to $31 \times 31 \mathrm{~cm}^{2}$.

This research work was supported by Politehnica University of Bucharest within the program National Grants GNaC 2018 ARUT, contract no ME15-18-01.

\section{References}

1. H. P. Garg, A. R. Shukla, Indrajit, Madhuri, R. C. Agnihotri and S. Chakravertty, Development of a Simple Low-Cost Solar Simulator for Indoor Collector Testing, Applied Energy 21 43-54, (1985)

2. Qinglong Meng, Yuan Wang, Linhua Zhang, Irradiance characteristics and optimization design of a large-scale solar simulator, Solar Energy 85 1758-1767, (2011)

3. Mahmoud Shatat, Abdulkarym Mayere, Saffa Riffat, A standardized Empirical Method of Testing Solar Simulator Coupled with Solar Tube and Concentrator Collectors, Int. J. of Thermal \& Environmental Engineering 5, No. 1 13-20, (2013)

4. Rahmat Awaludin Salam, Casmika Saputra, Elfi Yuliza, Irwan Meilano, Muhammad Miftahul Munir, Hamzah Latief, and Khairurrijal, Development of a Simple Low-Scale Solar Simulator and Its Light Distribution, 2016 International Conference on Instrumentation, Control and Automation (ICA), Institut Teknologi Bandung (ITB), Bandung, Indonesia, August 29-31, (2016)

5. Hazim Moria, Radiation distribution uniformization by optimized halogen lamps arrangement for a solar simulator, Proceedings of the International Conference on Industrial Engineering and Operations Management Rabat, Morocco, April 11-13, (2017)

6. R.W. Moss, G.S.F. Shire, P.C.Eames, P. Henshall, T.Hyde and F.Arya, Design and commissioning of a virtual image solar simulator for testing thermal collectors, Solar Energy 159:234-42, (2017)

7. Erkata Yandri, Uniformity characteristic and calibration of simple low cost compact halogen solar simulator for indoor experiments, International Journal of Low-Carbon Technologies, 13, 218-230, (2018) 